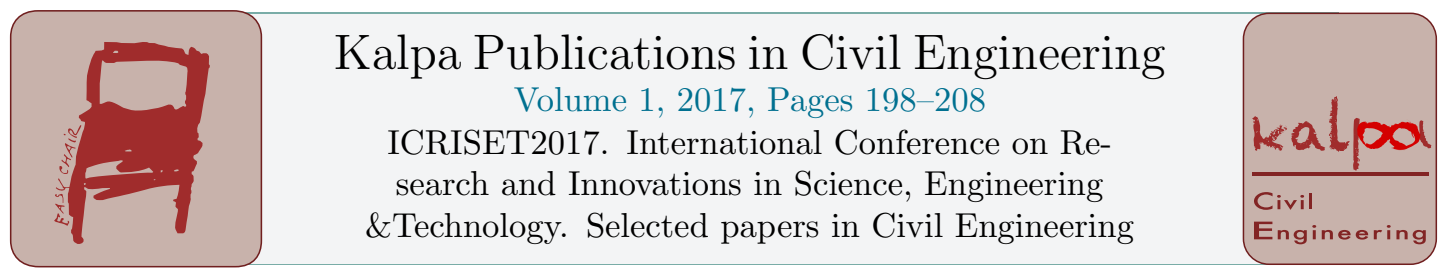

\title{
Performance of SIFCON with Steel Slag
}

\author{
Shashi Kant Sharma ${ }^{1}$, Aniruddha D. Chopadekar ${ }^{2 *}$ and Samarth Y. Bhatia ${ }^{2}$ \\ ${ }^{1}$ Assistant professor, Department of Civil Engineering, NIT Hamirpur, Himachal Pradesh, India \\ ${ }^{2}$ Student of M. Tech Civil engineering, NIT Hamirpur, Himachal Pradesh, India \\ ${ }^{1}$ shashi.pec@gmail.com, ${ }^{2 *}$ chopadekar.aniruddha@gmail.com
}

\begin{abstract}
Slurry infiltrated fibrous concrete (SIFCON) is a new and unique type of high performance concrete invented by Lankard in 1979, containing high percentage of fiber about $6 \%$ to $20 \%$ by volume. SIFCON possesses high strength as well as large ductility and has excellent potential for structural application. The matrix in SIFCON has no coarse aggregate but high cementitious content. The aim of study is to evaluate the performance of SIFCON mortar with lower fiber percentage and to minimize the fine aggregate usage by replacing it with industrial waste i.e. steel slag. Thereby, it also helps in effective disposal of industrial waste and helps in mitigating environmental pollution. The main objective of this study is to determine the effect of partial replacement of sand with steel slag on the mechanical properties of SIFCON mortar. The experimental program was carried out with $2 \%, 3 \%$ and $4 \%$ of fiber content by volume combined with replacement of sand by steel slag in proportion of $10 \%$ and $20 \%$ by weight. For this purpose, compressive strength, flexural strength, split tension and impact strength of SIFCON specimens were tested after 7 and 28 days of curing, yielding positive results.
\end{abstract}

\section{Introduction}

Slurry Infiltrated Fibrous CONcrete (SIFCON used herein after) is a fibrous concrete having high fiber content infiltrated with either cement slurry or cement mortar. SIFCON is a high performance concrete less than half a century old. Owing to the lesser time elapsed since its invention, very less research work has been performed to evaluate it on the grounds of durability and cost control. SIFCON possesses high toughness and impact resistance thereby rendering it suitable for blast resistant and impact resistant structures. Not only this, it can also be used as a good seismic retrofitting option. SIFCON is a concrete rich in cement matrix and fibrous content thus eliminating 
the coarse fraction. Elimination of coarser fraction and inclusion of large volume of fiber is a major diffrence between SIFCON and Fiber reinforced concrete (FRC). The amount of fibers required in normal FRC is less than 2\%, whereas in SIFCON the volume of fibers ranges from $6 \%$ to $20 \%$. The large quantity of fiber and cement increases the overall production and placement cost of SIFCON, thus reducing its use. In past, attempts have been made to reduce the cement content but keeping the binder phase intact, by replacing cement with mineral admixtures such as fly ash, silica fumes etc. In this study, the amount of fibers has been restricted to $2 \%, 3 \%$ and $4 \%$ of volume of concrete. Furthermore, the sand has been partially replaced by ground Steel slag (referred to as Steel slag sand) obtained from steel industry. Slag is a byproduct obtained from steel furnace. Its handling and disposal has long been a source of distress for steel industry, moreover it's highly detrimental for environment as well. This slag is an inert, strong and hard material which can be suitably used in construction industry. To be used, it can be crushed to finer fraction from its large sized boulders in replacement of river sand in conventional and high performance concrete. Fig. 1 shows the variations in the sizes of the steel slag. In the present study SIFCON specimens were prepared for compression, flexural and impact tests and evaluated after 7 and 28 days of curing under normal temperature and test conditions.

\section{Material used}

The materials used for this study conforms to the Indian standards. After analyzing the previous experiments conducted on SIFCON, materials with following specifications were used.

- Cement: OPC 53 Grade Cement of fineness 2\% Specific Gravity 3.10, Standard Consistency 35\%, IST and FST 35 and 480 minutes respectively.

- Fiber: Hook ended steel fibers of aspect ratio 60 and length $35 \mathrm{~mm}$.

- Sand: Locally available River Sand passing through $2.00 \mathrm{~mm}$ and retained on $0.075 \mathrm{~mm}$ sieve.

- Steel slag: Steel Slag from nearby steel manufacturing plant of specific gravity 2.89 , water absorption $12.21 \%$, passing through $2.00 \mathrm{~mm}$ and retained on $0.075 \mathrm{~mm}$.

- Water: Locally available drinking water was used for mixing and curing of specimens.

The properties of materials used are given in Table 1 and Table 2.

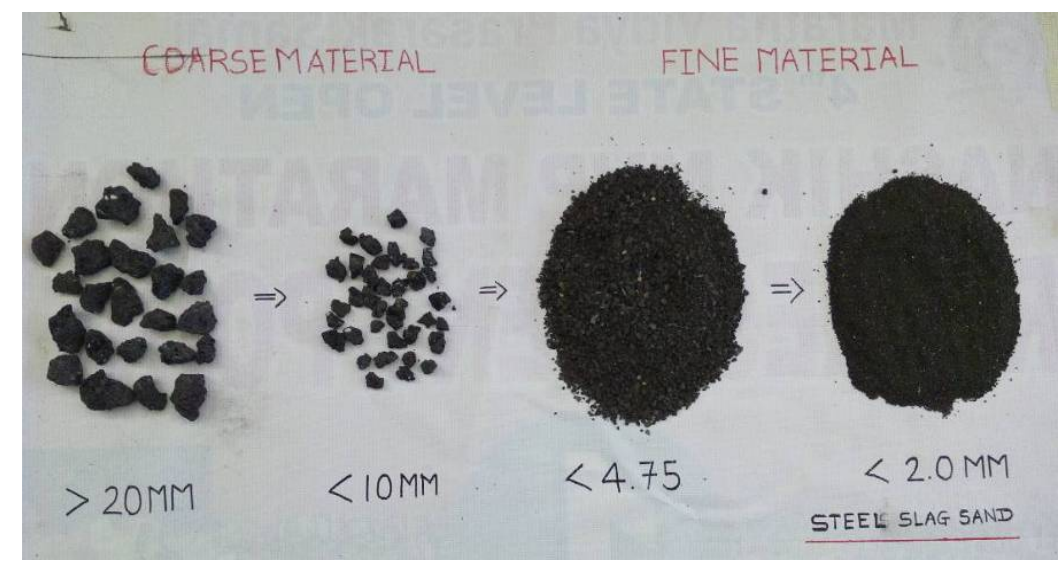

Figure 1 : Various sizes of steel slag available 
Performance of SIFCON... Dr. Shashi Kant Sharma, Aniruddha Chopadekar and Samarth Bhatia

\begin{tabular}{lr}
\hline \multicolumn{2}{c}{ Ordinary Portland Cement (OPC 53) } \\
\hline Standard Consistency (\%) & 35 \\
Initial Setting time (Min) & 35 \\
Final Setting time (Min) & 480 \\
Fineness (\%) & 2 \\
\hline \multicolumn{2}{c}{ Natural sand } \\
\hline \multicolumn{2}{c}{ Fineness Modules } \\
Water Absorption (\%) & 2.9 \\
Specific gravity & 1.42 \\
Silt content (\%) & 2.7 \\
Density (kg/m ${ }^{3}$ ) & 3 \\
\multicolumn{2}{c}{ Steel Slag } \\
\hline Fineness Modules & 1490 \\
Water Absorption (\%) & 2.95 \\
Specific gravity & 2.21 \\
Silt content (\%) & 2.89 \\
Density (kg/m ${ }^{3}$ ) & 2140 \\
Color & Dark \\
\hline $10 \%$ Steel slag and $90 \%$ Natural sand \\
\hline Fineness Modules \\
\hline $20 \%$ Steel slag and $80 \%$ Natural sand \\
\hline Fineness Modules
\end{tabular}

Table 1: Physical Properties of material used

\begin{tabular}{ccc}
\hline Content & Steel Slag (\%) & Cement OPC (\%) \\
\hline $\mathrm{CaO}$ & 41.69 & 64.2 \\
$\mathrm{SiO}$ & 33.82 & 22.0 \\
$\mathrm{~T}-\mathrm{Fe}$ & 0.42 & 3.0 \\
$\mathrm{MgO}$ & 7.40 & 1.5 \\
$\mathrm{Al}_{2} \mathrm{O}_{3}$ & 13.39 & 5.5 \\
$\mathrm{~S}$ & 0.81 & 2.0 \\
$\mathrm{P}_{2} \mathrm{O}_{5}$ & $<0.1$ & - \\
$\mathrm{MnO}$ & 0.3 & - \\
\hline
\end{tabular}

Table 2: Chemical composition of material used

\section{Mix proportions}

The matrix in SIFCON has no coarse aggregates, but a high cementitious content. There is no specific method for mix design of SIFCON. Generally the proportion of cement and sand used in SIFCON are $1: 1,1: 1.5$ or $1: 2$. For this study, cement and sand were mixed in a proportion of $1: 1$, with a water cement ratio of 0.40 . 
The specimens were cast with fiber content of $2 \%, 3 \%$ and $4 \%$ by volume fraction and by replacing sand with steel slag in proportion of $10 \%$ and $20 \%$ by weight and the obtained results were compared with control mix i.e. $100 \%$ natural sand specimens. Mix proportion for different percentage replacement of steel slag sand in SIFCON is given in Table 3.

\begin{tabular}{ccccccccc}
\hline Number & $\begin{array}{c}\text { Mix } \\
\text { proportion }\end{array}$ & $\begin{array}{c}\text { Replacement } \\
\text { Level (\%) }\end{array}$ & $\begin{array}{c}\text { W/C } \\
\text { ratio }\end{array}$ & Water & Cement & Sand & Steel slag & Fiber \\
\hline $\begin{array}{c}\text { SIFCON } \\
2\end{array}$ & $1: 1$ & 0 & 0.40 & 285.71 & 714.28 & 714.28 & 0 & 157 \\
& $1: 1$ & 10 & 0.40 & 285.71 & 714.28 & 642.85 & 71.42 & 157 \\
& $1: 1$ & 20 & 0.40 & 285.71 & 714.28 & 571.42 & 142.85 & 157 \\
\hline $\begin{array}{c}\text { SIFCON } \\
3\end{array}$ & $1: 1$ & 0 & 0.40 & 285.71 & 714.28 & 714.28 & 0 & 235.50 \\
& $1: 1$ & 10 & 0.40 & 285.71 & 714.28 & 642.85 & 71.42 & 235.50 \\
& $1: 1$ & 20 & 0.40 & 285.71 & 714.28 & 570.42 & 142.85 & 235.50 \\
\hline $\begin{array}{c}\text { SIFCON } \\
4\end{array}$ & $1: 1$ & 0 & 0.40 & 285.71 & 714.28 & 714.28 & 0 & 314 \\
& $1: 1$ & 10 & 0.40 & 285.71 & 714.28 & 642.85 & 71.42 & 314 \\
\hline
\end{tabular}

Table 3: Mix Proportion

\section{Procedure for casting specimen}

Due to extremely high fiber content in SIFCON the mixing of steel fibers becomes a difficult task and it cannot be mixed as easily as in the case of FRC. So a special method for the SIFCON production has been used for this study. Dry mixing of weighted cement and sand is done meticulously in a pan. Water is added in the dry mix corresponding to water-cement ratio of 0.40 . Water is to be added in parts. First, a thin layer of mortar with fluid consistency is placed at the bottom of the previously lubricated mould. Next, a layer of steel fiber is placed on the preplaced slurry. Again, slurry is infiltrated on to steel fiber layer and proper compaction is done by hand tamping. The entire mould is filled with alternate layers of slurry and steel fibers followed by surface finishing. The specimens were mixed compacted and cast carefully by following this procedure. The specimens were demoulded after 24 hours and cured for 7 and 28 days.

\section{Test Program}

The test program consisted of testing three specimens per test, each for 7 and 28 day. The sand was replaced with steel slag in the proportion of $10 \%$ and $20 \%$ by weight, keeping the proportions of other constituents constant. The specimen results were compared with control SIFCON specimens. The details of the tests conducted on fresh and hardened SIFCON specimens are as follows: 


\subsection{Flow Test}

To check the Fluidity, viscosity and filling ability without bleeding and segregation of cement mortar, Slump flow test was conducted. In this test inverted slumpcone is filled with mortar slurry and lifted to a height of $1.0 \mathrm{~m}$. The diameter of spread mortar occupied on plain surface is measured in two mutually perpendicular directions as shown in fig. 2. The average of these two is taken as the diameter of slump spread. For sufficient filling ability without bleeding and segregation required spread diameter should be between $350 \mathrm{~mm}$ to $380 \mathrm{~mm}$. Flow test on fresh cement mortar to be used in casting SIFCON specimens were carried out with varying percentages of steel slag replacement.

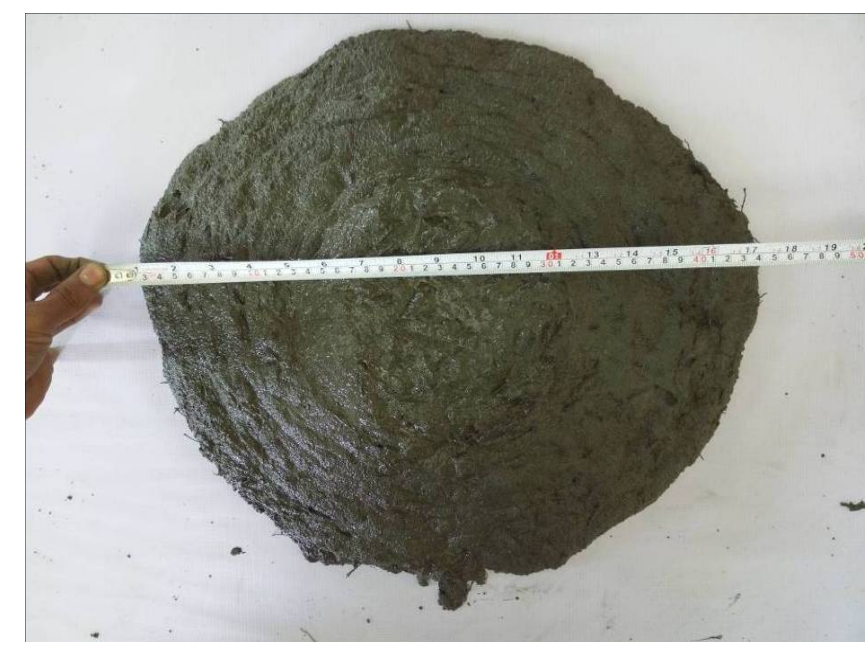

Figure 2: Measurement of slump flow

\subsection{Compressive strength test}

The compressive strength was carried out as per IS 516:1959. The test was conducted on three cubes of size $100 \times 100 \times 100 \mathrm{~mm}$ for 7 and 28 days on compression testing machine.

\subsection{Flexural strength test}

Flexural test was carried out on prismatic specimens of size 100 x 100 × $500 \mathrm{~mm}$ using Universal Testing Machine as per IS 519:1959.

\subsection{Split Tensile strength test}

Split tension test was carried out on specimens of $100 \mathrm{~mm}$ diameter and $200 \mathrm{~mm}$ height on compression testing machine as per IS 516:1959.

\subsection{Impact Energy test}

Impact Energy test was carried out on test specimens of $100 \mathrm{~mm}$ diameter and $50 \mathrm{~mm}$ height on impact testing machine, at 7 and 28 days. Drop weight type impact testing machine was used in accordance with method developed by Eren (1999). This machine (Fig. 3) is a combination of 
aggregate impact value test machine and drop weight type test apparatus as recommended by ACI 544:1987.

The drop hammer for this test weighs $13.5 \mathrm{~kg}$, and it is lifted and dropped from a height of 380 $\mathrm{mm}$. Three cylinders were tested at 7 and 28 days age, and number of blows required to cause the first visible crack and ultimate failure was recorded.

First crack is defined as the first visible crack in the specimen under testing while the ultimate failure is reached when the cracks have opened up sufficiently to make the specimens touch each of the four positioning lugs at the base plate Fig.4 shows the specimens after failure by impact energy test.

Energy imparted to the specimen per blow is calculated by equation (1).

$$
\mathrm{EI}=1 / 2 \mathrm{M} \mathrm{V}^{2} \mathrm{~N}
$$

Where;

$\mathrm{EI}=$ Impact energy $(\mathrm{N}-\mathrm{m})$,

$\mathrm{M}=$ Mass of drop hammer $(\mathrm{kg})$,

$\mathrm{V}=$ Impact velocity $=1.8088(\mathrm{~m} / \mathrm{s})$, and

$\mathrm{N}=$ Number of blows required for ultimate failure.

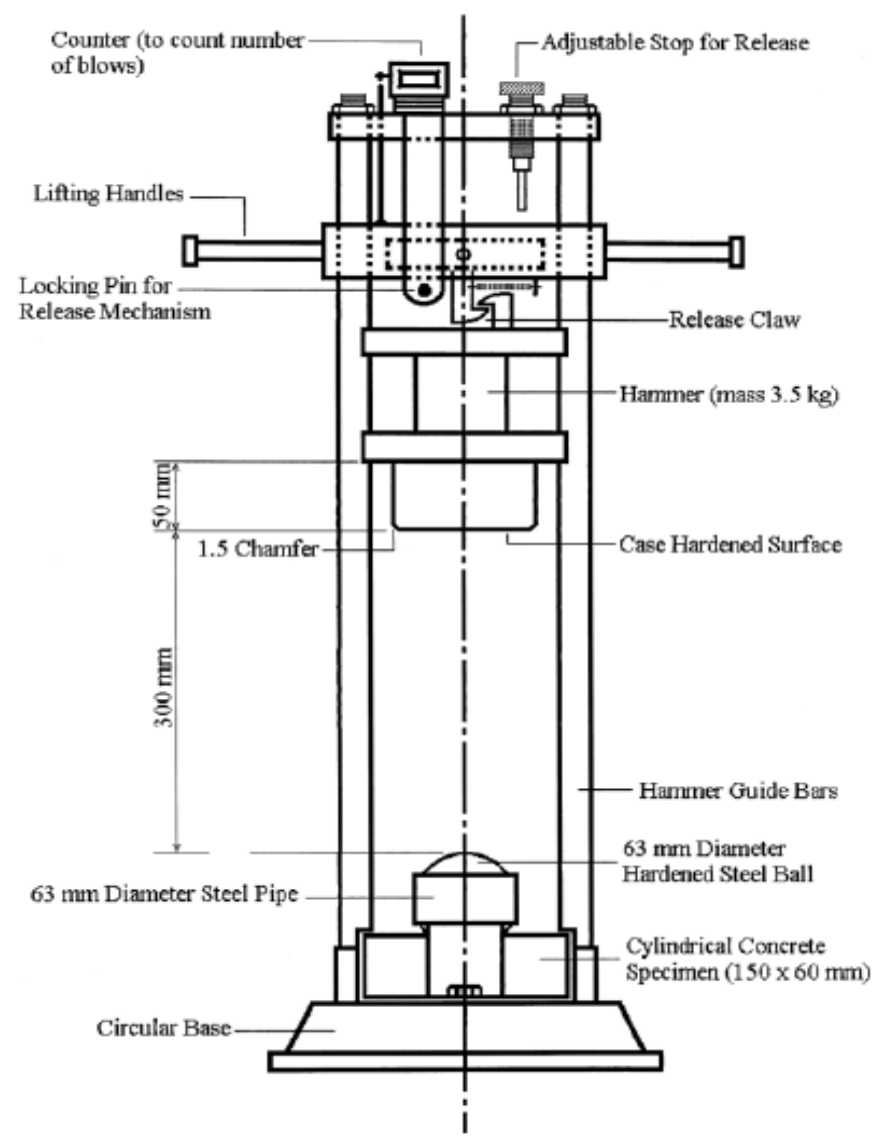

Figure 3: Assembly for Impact energy test 


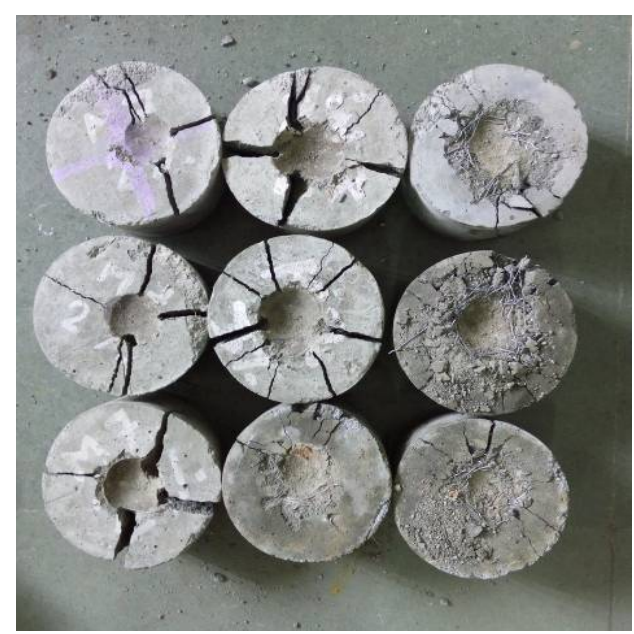

Figure 4: Impact Energy test specimen

\section{Result and Discussion}

The results of SIFCON for $2 \%, 3 \%$ and $4 \%$ fiber with $10 \%$ and $20 \%$ replacement of natural sand by steel slag are compared with the control mix having zero percentage of sand replacement and same fiber content. The results obtained from the study are shown in the Table 5 and subsequent discussion is presented as follows.

\subsection{Compressive strength}

1. Using $2 \%, 3 \%$ and $4 \%$ fiber by volume with $10 \%$ replacement of sand by steel slag for 7 days compressive strength increased up to $2.95 \%, 13.22 \%$ and $14.28 \%$ respectively.

2. With $2 \%, 3 \%$ and $4 \%$ fiber by volume with $20 \%$ replacement of sand by steel slag for 7 days compressive strength reduced up to $31.37 \%, 18.16 \%$ and $2.12 \%$ respectively.

3. Utilizing $2 \%, 3 \%$ and $4 \%$ fiber by volume with $10 \%$ replacement of sand by steel slag for 28 days compressive strength increased up by $12.60 \%, 8.24 \%$ and $10.91 \%$ respectively.

4. Usage of $2 \%, 3 \%$ and $4 \%$ fiber by volume with $20 \%$ replacement of sand by steel slag for 28 days compressive strength reduced up to $8.74 \%, 4.03 \%$ and $5.62 \%$ respectively.

\subsection{Flexural strength}

1. Using 2, 3 and 4\% fiber by volume with $10 \%$ replacement of sand by steel slag for 7 days Flexural strength increased up to $47.40 \%, 52.55 \%$ and $1.17 \%$ respectively.

2. With 2, 3 and 4\% fiber by volume with $20 \%$ replacement of sand by steel slag for 7 days Flexural strength increased up to $32.47 \%, 19.07 \%$ and $6.59 \%$ respectively.

3. Utilizing $2 \%, 3 \%$ and $4 \%$ fiber by volume with $10 \%$ replacement of sand by steel slag for 28 days Flexural strength increased up by $46.97 \%, 26.41 \%$ and $1.64 \%$ respectively.

4. Usage of $2 \%, 3 \%$ and $4 \%$ fiber by volume with $20 \%$ replacement of sand by steel slag for 28 days Flexural strength increased up to $3.80 \%, 25.90 \%$ and $2.93 \%$ respectively. 
Performance of SIFCON... Dr. Shashi Kant Sharma, Aniruddha Chopadekar and Samarth Bhatia

\begin{tabular}{|c|c|c|c|c|c|c|c|}
\hline \multirow[b]{2}{*}{ Property } & \multirow[b]{2}{*}{ Fiber $\%$} & \multicolumn{3}{|c|}{7 Day } & \multicolumn{3}{|c|}{28 Day } \\
\hline & & Control & $10 \%$ slag & $20 \%$ slag & Control & $10 \%$ slag & $20 \%$ slag \\
\hline \multirow{3}{*}{$\begin{array}{l}\text { Compressive } \\
\text { strength } \\
\text { (Mpa) }\end{array}$} & 2 & 31.83 & 32.77 & 24.23 & 44.05 & 49.60 & 40.20 \\
\hline & 3 & 32.53 & 36.83 & 27.53 & 54.60 & 59.50 & 57.10 \\
\hline & 4 & 35.57 & 39.80 & 34.83 & 63.80 & 70.76 & 60.40 \\
\hline \multirow{3}{*}{$\begin{array}{l}\text { Split tension } \\
\text { strength } \\
\text { (Mpa) }\end{array}$} & 2 & 4.16 & 5.66 & 4.67 & 4.95 & 6.73 & 4.74 \\
\hline & 3 & 5.14 & 5.68 & 5.60 & 7.11 & 7.23 & 6.62 \\
\hline & 4 & 6.05 & 7.29 & 6.97 & 8.65 & 10.41 & 8.20 \\
\hline \multirow{3}{*}{$\begin{array}{c}\text { Flexural } \\
\text { strength } \\
(\mathrm{Mpa})\end{array}$} & 2 & 7.30 & 10.76 & 9.67 & 9.75 & 14.33 & 10.12 \\
\hline & 3 & 9.23 & 14.08 & 10.99 & 12.28 & 15.53 & 15.46 \\
\hline & 4 & 15.32 & 15.50 & 16.33 & 18.08 & 18.29 & 18.61 \\
\hline \multirow{3}{*}{$\begin{array}{c}\text { Impact } \\
\text { energy (N.m) }\end{array}$} & 2 & 435.14 & 564.92 & 570.29 & 1368.02 & 1434.21 & 1456.28 \\
\hline & 3 & 1106.94 & 2099.38 & 2129.85 & 1875.50 & 2909.83 & 3129.85 \\
\hline & 4 & 2229.16 & 2340.13 & 2434.67 & 2329.35 & 3313.13 & 3343.67 \\
\hline
\end{tabular}

Table 4: Test Results

\subsection{Split tensile strength}

1. Using $2 \%, 3 \%$ and $4 \%$ fiber by volume with $10 \%$ replacement of sand by steel slag for 7 days Split tensile strength increased up to $36.06 \%, 1.43 \%$ and $20.50 \%$ respectively.

2. With $2 \%, 3 \%$ and $4 \%$ fiber by volume with $20 \%$ replacement of sand by steel slag for 7 days Split tensile strength increased up to $10.90 \%, 4.16 \%$ and $6.04 \%$ respectively.

3. Utilizing $2 \%, 3 \%$ and $4 \%$ fiber by volume with $10 \%$ replacement of sand by steel slag for 28 days Split tensile strength increased up by $40.00 \%, 1.69 \%$ and $20.35 \%$ respectively.

4. Usage of $2 \%, 3 \%$ and $4 \%$ fiber by volume with $20 \%$ replacement of sand by steel slag for 28 days Split tensile strength reduced up to $4.20 \%, 6.89 \%$ and $5.20 \%$ respectively.

\subsection{Impact Energy}

1. Using $2 \%, 3 \%$ and $4 \%$ fiber by volume with $10 \%$ replacement of sand by steel slag for 7 days Impact energy increased up to $29.83 \%, 89.66 \%$ and $4.98 \%$ respectively.

2. With $2 \%, 3 \%$ and $4 \%$ fiber by volume with $20 \%$ replacement of sand by steel slag for 7 days Impact energy reduced up to $31.06 \%, 92.41 \%$ and $9.22 \%$ respectively.

3. With $2 \%, 3 \%$ and $4 \%$ fiber by volume with $20 \%$ replacement of sand by steel slag for 28 days Impact energy reduced up to $4.84 \%, 55.15 \%$ and $42.23 \%$ respectively. 
4. With $2 \%, 3 \%$ and $4 \%$ fiber by volume with $20 \%$ replacement of sand by steel slag for 28 days Impact energy reduced up to $6.45 \%, 66.88 \%$ and $43.55 \%$ respectively.

From the above results, it is found that as the fiber content increases the strength parameters i.e. compressive strength, flexural strength and impact energy also increases. While discussing about the replacement level of the natural sand with steel slag, there is no reduction in strength found, rather the strength increases up to certain extent. $10 \%$ replacement is found to be optimum and gives the best results. The size of the steel slag used for the study is less than $2.00 \mathrm{~mm}$, which fills the voids between sand particles and helps in improving the strength of concrete SIFCON. On a contrary if the replacement level is increased beyond optimum limit, it results in additional voids and becomes one of the reasons for strength reduction.

\section{Failure Pattern}

The failure pattern of conventional concrete and that of SIFCON specimens varies greatly. On one hand the failure of conventional concrete is brittle while on the other hand SIFCON shows ductile performance which is an added advantage of SIFCON. The failure of specimens under compression, split tension and flexure are shown in fig 5, fig 6 and fig 7 respectively and discussed below.

\subsection{Failure of cubical specimen under compression}

When compared to the standard control conventional concrete SIFCON displays failure after developing vertical cracks at edges, i.e. cup and cone formation.

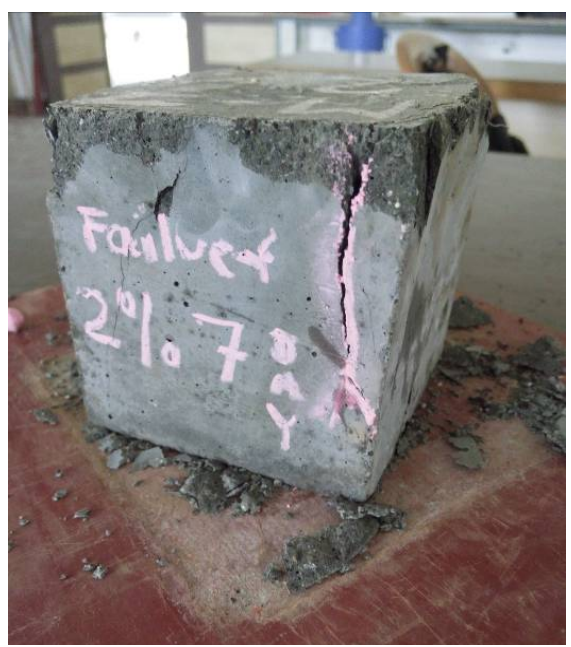

Figure 5: Failure of cube specimen under compression

\subsection{Failure of cylindrical specimen under compression in Split tensile strength test}

SIFCON specimens' shows bulging while ordinary concrete shows splitting of specimen into two halves throughout. 


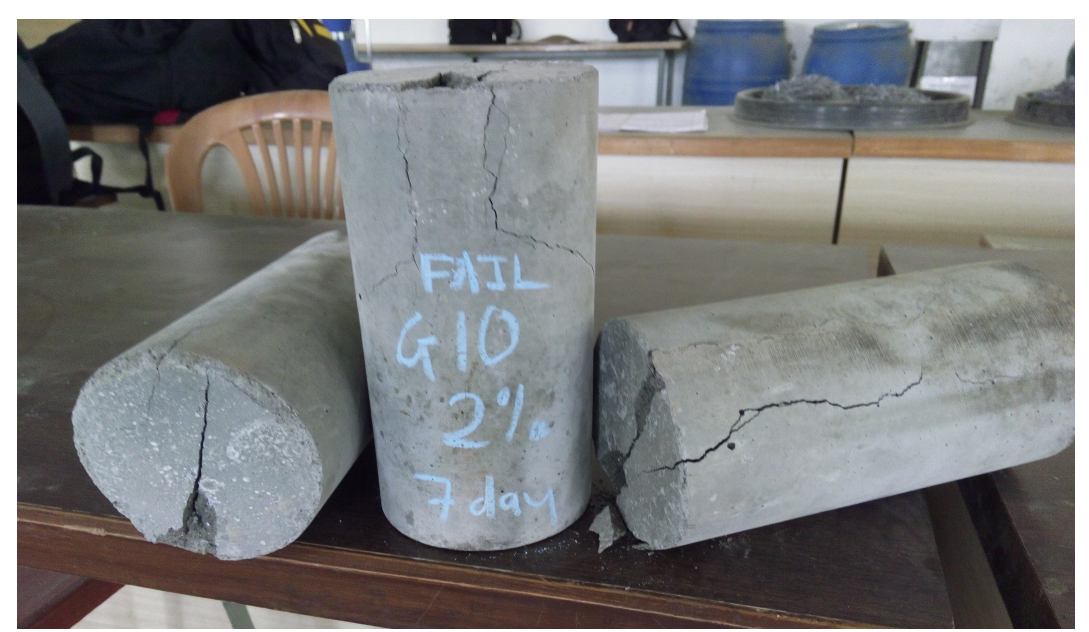

Figure 6: Failure of cylindrical specimen under compression in split tensile strength test

\subsection{Failure of beam specimen under Flexural strength test}

On one hand when conventional concrete shows almost zero or negligible deflection, the SIFCON specimen shows exceptional ductile performance showing deflection of almost $7 \mathrm{~mm}$. Further tests and experimentations show that as the age of concrete increases the deflection increases. As percentage of steel fiber increases the deflection also increases. This shows that the presence of steel fibers prevents the complete shear failure of beams. Diagonal cracks are formed below the point of application of load.

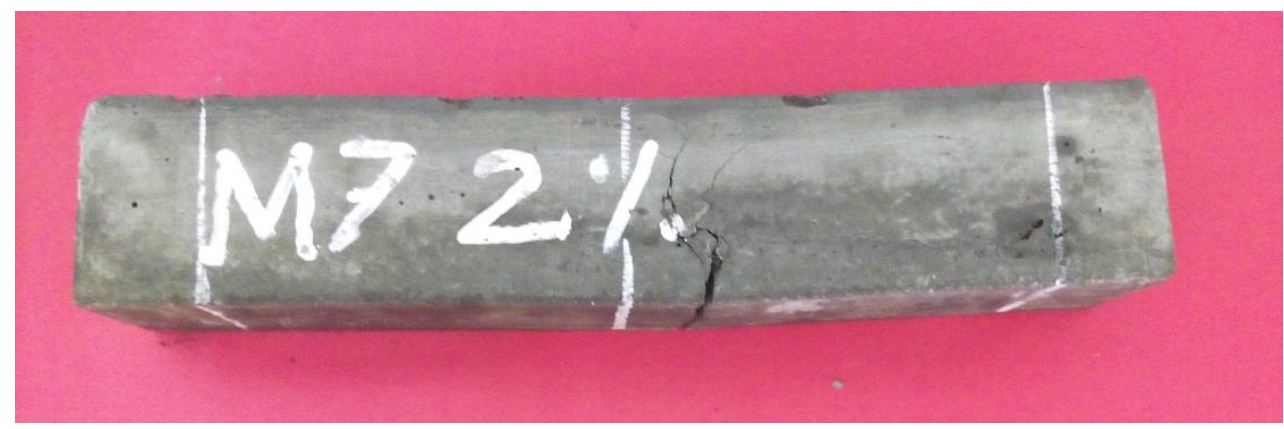

Figure 7: Failure of beam specimen under flexural tensile strength test

\section{Conclusion}

After the detailed experimentation and analysis of the result we have inferred that;

- SIFCON shows performance enhancement with lower percentages of steel fiber content by addition of additives such as steel slag. However, addition of steel slag reduces workability.

- An increase in the compressive, tensile, flexural and impact strength of SIFCON specimens were found in this study. 
Performance of SIFCON...

Dr. Shashi Kant Sharma, Aniruddha Chopadekar and Samarth Bhatia

- Moreover, the $10 \%$ sand replacement was found to be optimum, except for the case of impact specimens where a direct relationship was observed between percentage replacement of steel slag and energy absorbed by specimen.

- When compared with control specimens of normal concrete the flexural behavior of SIFCON was observed to be more ductile.

\section{References}

Antonio Nanni,"Properties of aramid-fiber reinforced concrete and SIFCON" Journal of materials in civil engineering ASCE-1992, vol. 4, pp :1-15

Arun Aniyan Thomas and Jeena Mathews, "Strength and behaviour of SIFCON with different types of fibers" Journal of proceedings of the international conference on emerging trends in engineering and management (icetem14), vol. 5, pp 25-30, 2014

Bhavna Tripathi, Anurag Misra and Sandeep Chaudhari, "Strength and abrasion characteristics of ISF slag concrete" Journal of materials in civil engineering ASCE, pp 1611-1618, November 2013

Folarin T. Olorunsogo and Peter J. Wainwright, "Effect of GGBFS particle-size distribution on mortar compressive strength" Journal of materials in civil engineering ASCE, vol. 10, pp 180-187, 1998

Halit Yazıc1, Serdar Aydin, Huseyin Yigiter and Mert Y. Yardimci, "Improvement on SIFCON performance by fiber orientation and highvolume mineral admixtures" Journal of materials in civil engineering ASCE, vol. 22, 2010, pp 1093-1101

Halit Yazic1, Serdar Aydin, Huseyin Yigiter and Bulent Baradan, "Autoclaved SIFCON with high volume class c fly ash binder phase” Journal of cement and concrete research, vol. 36, pp 481- 486, 2006

K. Ganesh Babu and V. Sree Rama Kumar. "Efficiency of GGBS in concrete" Journal of ocean engineering centre, Indian institute of technology, chennai 600 036, India March 2000, pp 1032-1036

L Svermova and P. J. M. Bartos "Development of insitu SIFCON for connections in precast concrete and seismic resistant structures" Journal of conference on our world in concrete \& structures, Singapore, pp. 552-559, Aug 2002

Mohamed Maalej, Ser Tong Quek and Jing Zhang "Behavior of hybrid-fiber engineered cementitious composites subjected to dynamictensile loadingand projectile impact" Journal of materials in civil engineering ASCE, pp 17: 143-152, March 2005

R. Breitenbficher "Repair of environmental constructions with the high performance concrete SIFCON", Journal of Material in civil engineering, vol. 17, pp 143-152, 2005

V. S. Parameswaran, T. S. Krishnamoorthy, K. Balasubramanian and Santhi Gangadar, "Studies on slurry-infiltrated fibrous concrete (SIFCON) " Journal of transportation research record, pp. 57-63

$\mathrm{Yu}$-fei $\mathrm{Wu}$, Jia-Fei Jiang and Kang Liu. "Perforated SIFCON blocks - an extraordinarily ductile material ideal for use in compression yielding structural systems" Journal of construction and building materials, vol. 24, pp 2454-2465, 2010

IS 516 (1959): Method of Tests for Strength of Concrete 